\title{
CORRESPONDENCE
}

\section{Questionnaires in asthma epidemiology}

\section{To the Editor:}

In epidemiological studies of asthma, questionnaires are widely accepted methods of identifying affected subjects. International Study of Asthma and Allergies in Childhood (ISAAC) is an international project aiming to determine the prevalence of asthma, allergic rhinitis and eczema in children living in different countries [1].

The written questionnaire includes questions on respiratory symptoms such as frequency and severity of wheezing and cough. It ends with a question about diagnosed asthma.

Published results of the worldwide ISAAC study pointed to a large variation in the prevalence of self-reported symptoms of asthma [2-4]. The question concerning whether the child had ever had asthma ranged 1.6-28.2\%. In our town, physicians are reluctant to diagnose children as having asthma, if they have recurrent wheezing.

The frequency of asthma in Curitiba was 6.5 and 8.6\%, respectively for 6-7 and 13-14 yr olds using the ISAAC

Table 1. - Frequency of active asthma symptoms

\begin{tabular}{|c|c|c|}
\hline \multirow[b]{2}{*}{ Criteria } & \multicolumn{2}{|c|}{ Age group } \\
\hline & $\begin{array}{l}6-7 \text { yrs } \\
(n=1666)\end{array}$ & $\begin{array}{l}13-14 \text { yrs } \\
(n=2946)\end{array}$ \\
\hline $\begin{array}{l}\text { More than four attacks of } \\
\text { wheezing in the last } 12 \text { months }\end{array}$ & $85(5.1)$ & $101(3.4)$ \\
\hline $\begin{array}{l}\text { One to three attacks, in addition } \\
\text { to disturbed sleep due to } \\
\text { wheezing }\end{array}$ & $161(9.7)$ & $190(6.5)$ \\
\hline $\begin{array}{l}\text { One to three attacks, never } \\
\text { woken with wheezing, but with } \\
\text { dry cough at night and } \\
\text { wheezy after exercise }\end{array}$ & $15(0.9)$ & $50(1.7)$ \\
\hline Total & $261(15.7)$ & $341(11.6)$ \\
\hline
\end{tabular}

Data are presented as number with percentages in parentheses. questionnaire. This is definitely an underestimation of the prevalence of asthma.

Thus, to assess a more realistic prevalence, we selected questions that could be considered strongly suggestive of a diagnosis of asthma. They are presented in table 1.

This cumulative frequency was then named "probable asthma". Although there is a tendency to pick up more severe asthma, it may not detect all cases of asthma. However, it is more informative than relying on the question "have you ever had asthma?" We suggest that "probable asthma" is closer to actual figures and may be helpful in comparing point prevalence of active asthma in different countries.

\section{N.A Rosario, F.P. Ferrari}

Dept of Paediatrics, Federal University of Parana, Curitiba, Brazil.

\section{References}

1. Asher MI, Keil U, Anderson HR, et al. International study of asthma and allergies in childhood (ISAAC): rationale and methods. Eur Respir J 1995; 8: 483-491.

2. Pearce N, Weiland SK, Keil U, et al. Self-reported prevalence of asthma symptoms in children in Australia, England, Germany and New Zealand: an international comparison using the ISAAC protocol. Eur Respir $J$ 1993; 6: 1455-1461

3. Burr ML, Limb ES, Andrae S, Barry DM, Nagel F. Childhood asthma in four countries: a comparative survey. Int $J$ Epidemiol 1994; 23: 341-347.

4. Asher MI, Anderson HR, Stewart AW, et al Worldwide variations in the prevalence of asthma symptoms: the International Study of Asthma and Allergies in Childhood (ISAAC). Eur Respir J 1998; 12: 315-335. 